\title{
DEVELOPMENT OF A3-AXIS CNC MILLING MACHINE WITH AN OPEN SOURCE CONTROLLER
}

\author{
Akshay R Sonawane ${ }^{1}$, Arun Bhiva Rane ${ }^{2}$, D. S. S. Sudhakar ${ }^{3}$ \\ ${ }^{1}$ Student of Masters of Engineering, Department of Mechanical Engineering, Fr.C.Rodrigues College of Engineering, \\ Maharashtra, India \\ ${ }^{2}$ Professor, Department of Production Engineering, Fr.C.Rodrigues College of Engineering, Maharashtra, India \\ ${ }^{3}$ Head of Department, Department of Production Engineering, Fr.C.Rodrigues College of Engineering, Maharashtra, \\ India
}

\begin{abstract}
This report presents one of the application performed by Arduino Uno when sandwiched with Grbl shield which is a high performance open source CNC controller written in optimized C-language. Here in this paper a file with extension .jpeg or .png, or .pdf is imported in an open source Aspire software which converts it into .txt or .prt file. Vectors of the imported file is traced accordingly, followed by modelling and manufacturing procedures. Once the simulation of the manufacturing file is visualized in Aspire software then G-code file is generated using post processing operation, this G-code file is saved with .txt extension. The Gcode file is then browsed in Universal G-code sender software coupled to Grbl shield v0.9j and Arduino board through a laptop serial port, G-code visualizer option is available on Universal G-code sender software to visualize the manufacturing steps along with the simulation. In this way proprietory control of a controller is eliminated, and CNC machine is made user friendly.
\end{abstract}

Keywords: CAD; Open control; Aspire;CAM; Arduino Uno; Grbl Shield V0.9; Universal G-code sender.

\section{BACKGROUND}

Flexible and specialized manufacturing industry needs the use of automated robotic systems and CNC machines.(Rane et al. 2017) [19]. There has been an emergence of the condition to select the efficient and obsolete the degraded. Instantly changing dynamic lifestyle with technology embedded gadgets which has short life span are popularly accepted nowadays. As a result, if computer integrated manufacturing (CIM) and flexible manufacturing systems (FMS) forms a structure then, computer aided design $(\mathrm{CAD})$, computer aided manufacturing (CAM), robots and CNC technologies acts as their main organs. Rane et al. (2016) have presented FMS for throughput enhancement [18].

Alpha-numeric data is coded in a program which is prepared to control motions and functions of a CNC machine. Rane et al. (2005) have successfully eliminated these codes [17]. The motion of the tool and workpiece, turning the spindle and coolant on/off, maintaining the feed rate for machining, controlling the depth of cut, etc. are controlled by CNC machine. Allowing flexibility and accuracy in manufacturing with reduction in production time, using simple fixturing and contour machining along with successful lean implementation are some of the benefits of CNC machine.(Rane et al. 2016, 2015) [15], [16].

Along with the advantages there are a few drawbacks as well, which includes high initial cost and maintenance cost, necessity of a skilled programmer. There are wide applications of CNC machines like CNC sheet metal press, $\mathrm{CNC}$ lathe, $\mathrm{CNC}$ laser cut, $\mathrm{CNC}$ tube bend, $\mathrm{CNC}$ mill, $\mathrm{CNC}$ grinding machine etc. Automatic turning center, as well as machining center are also developed using CNC equipped with automation. Also along with this, CNC is also used in assembly lines, measuring the co-ordinates, and precise welding processes.Rane et al. (2016, 2017) [18,21] has demonstrated the applications of $\mathrm{CNC}$ for improving the performance of manufacturing plant.

In this paper, a 3-axis CNC mill prototype is developed for user friendly experiments with open controller. Arduino equipped microcontroller is connected with the CNC shield which has drivers mounted on it to initiate the actuators, here nema-17 stepper motors are used as actuators, and for execution of participatory codes and miscellaneous codes an open source software is utilized.The controller will then convert these codes into step pulses, which will be sent as an input to actuators (stepper motors) of CNC machine. These actuators will then convert the incoming signals into rotary motions.

Rane et al. (2016) [22] have improved the performance of line using CNC. Nowadays more and more machines are being converted in CNC machines due to their high accuracy, high precision, less setting time and greater repeatability. One aspect of using CNC is that unskilled or semi-skilled labours can also use it effectively. According to Rane et al. (2017) [23] CNC can be used for batch as well as mass production. The basic controlling of a $\mathrm{CNC}$ is same as that of a printer. As CNC machines are bigger in size they are mostly used in workshops. Sarda et al. (2015) [24] have proposed use of CNC in assembly line. 


\section{MOTIVATION}

A CNC machine which is available in industry is very expensive, mostly imported from abroad. Also along with CNC machines its controllers are also constricted to their developers, where the end user cannot make any changes if he opts to, as the controller is totally controlled by its owners.

The motivation behind this project comes from an idea where an end user can control the functioning of the controller of CNC machine with his own wish and need. User friendly nature of the controller will enhance the capability to modify the codes as per the requirements.

G-codes and M-codes generated by the controllers are not universal, so to generate an open source CNC controller and to make them universal for better understanding of complex nature of $\mathrm{CNC}$ machine, here in this project a mini 3 axis CNC mill prototype is developed.

The fascination lies in the joy of creating something tangible making a machine which further pushes the boundaries of creativity, ease of operation and coding for simpler program can be an additive advantage.

Small institutions lacks the capability of vocational training as the ordering cost, holding cost and maintenance cost of $\mathrm{CNC}$ machine is too high. Once a mini prototype of CNC machine is made available, it will help to simulate manufacturing (Rane et al. 2014) [25], which will further cater into creativity and future innovation.

\section{OBJECTIVES OF THE STUDY}

Following issues are to be addressed in this project:

1. In this project, it is intended to develop controller which will be universal and takes preparatory codes (G-code) and miscellaneous codes (M-code) generated by any CAD/CAM software.

2. To convert .jpeg or .png image of a rectangle or circular profile into drawing file (.dxf or .prt) and generate Gcode file for the same after importing it in UG NX 10.

3. To develop a simple 3 axis $\mathrm{CNC}$ machine which will incorporate four $2.6 \mathrm{~kg} / \mathrm{cm}$ stepper motors, Arduino Uno and Grbl v0.9 + 4x DRV8825 driver with 4 aluminium heat sinks hardware, universal G-code sender software.

4. Timing belt error to be minimized.

5. To increase the accuracy for precise machining.

6. To machine a profile with features like bore, drill or face on soft material like medium density fiberboard, with atleast $5 \mathrm{~mm}$ depth accurately.

\section{BRIEF LITERATURE REVIEW}

Banzi et al (2015) [14], proposed Arduino based open source platform with easy to use hardware and software. Sundar Pandian et al (2014) [1], demonstrated an Open source G-code interpreter i.e., GRBL controller which acts as an inspiration to work on the production system with low cost. The GRBL team implemented user friendly innovation on interpreting the CNC G-codes using Arduino based microcontroller system.

Dr B.Jaychandraiah et al (2014) [5], have fabricated CNC router containing 3-axis. Patrick Hood-Daniel (2009) [11] and James Floyd Kelly in the book My DIY CNC (2011) have proposed guidelines on how to build a 3 axis CNC machine along with construction manual.

Torjus spilling (2014) [13], presented his master's thesis on self-improving CNC machine, author has also given guidelines to Build It Yourself 3 axis CNC machine along with the hardware and software information. Alian Albert (2011) [9], has studied history of CNC machines, information regarding CAD/CAM softwares and suggested for various components to be used in a router.

Martin Kennedy (2016) [10], has proposed the guidelines to build a 3 axis CNC milling machine. Dipayan Dey et al (2016) [4], have proposed better motor drivers to get compatible with softwares with more micro stepping capability.

Comprehensive plans and construction manual is proposed in DIY CNC (2011) [12]. R.Sundaramoorthy et al (2016), has studied for different types of aluminium alloys used in CNC machine [7].

Dhaval B Patel et al (2014) [3], presented a review of 3 axis DIY-CNC machine and suggested for the selection of belt drive, sliding system, comparison of different stepper motor drivers, etc. Sakib Shaukat Surguroh et al (2016) [6], has addressed an open source code for 2 axis CNC machine.

Rajendra Rajput et al (2016) [2], demonstrated the comparison of CNC controllers viz., Fanuc 21M, Sinumerik 840D, Heidenhain TNC 426. Kajal Madekar et al. (2016) [8] shows the usage of Arduino controller platform with ATMEGA 328 core microcontroller.

\section{RESEARCH GAP AND PROPOSED PROBLEM STATEMENT}

Timing belt error is one of the key problem for maintaining accuracy and precision in CNC machine Sakib et al (2016) [6], In this project, tension in the belt is so adjusted that the error occurred earlier will be minimized, also for better accuracy vertical axis ( $\mathrm{z}$ axis) is to be fabricated using screw drive instead of belt drive and belt drive is kept only for $\mathrm{x}$ axis and y axis travel.

As the load of the gantry is completely on y axis travel, so in this project instead of using one stepper motor, two stepper motors are used for $y$ axis travel, so that the load occurred during travel will get equally balanced and the bits are accurately placed while machining.

Instead of sliding rods a $2 \mathrm{~mm}$ aluminium sliding rails are used in this work because linear bearing on sliding rods may 
sometimes cause disruption due to high frictional load also the deposition of atmospheric dust onto the inner surfaces of the bearing results into blockage of the smooth movement of the sliding bearings.

Thus based on the above research gap the problem statement is to develop a simple three axis open source CNC machine which will incorporate four $2.6 \mathrm{~kg} / \mathrm{cm}$ stepper motors, Arduino Uno and GRBL v0.9 + 4x DRV8825 drivers with 4 aluminium heat sinks hardware and universal G-code sender software.

\section{THE CONTROLLER}

The brain of CNC system is its controller.Fig 1 shows open loop system used for this project. Step/direction in the form of signals is given by the computer to the controller, arduino is used as controller in this project which receives conditioned signals and converts this step/direction signals into pulses and these pulses helps Grbl shield to compute the steps for axial motion, ultimately actuating the stepper motors for the desired job.

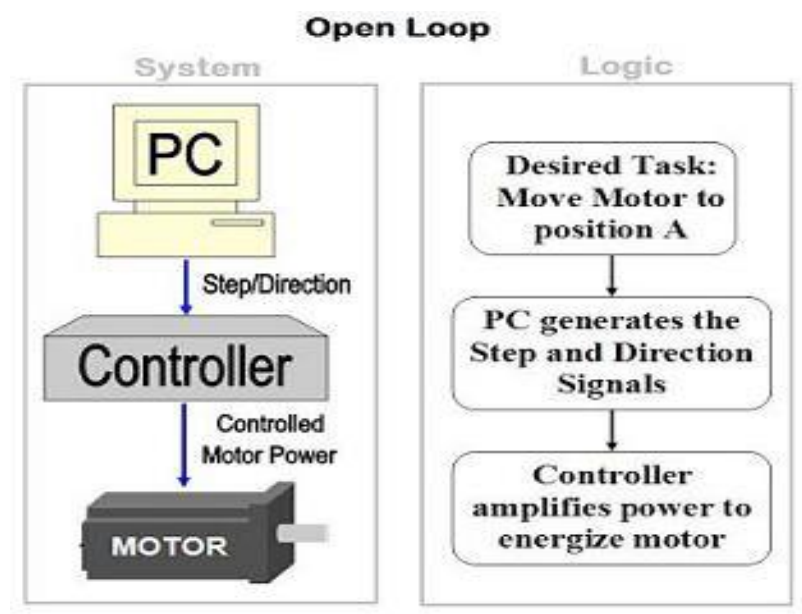

Fig -1: Open loop system [www.cncroutersource.com

(2011)]

The primary function of the controller is to accept and interpret conditioned signals sent via computer into desired mechanical activity. Several components makes up a controller and every component works unitedly to obtain the required mechanical activity, here stepper motor movement is the mechanical activity. The control system may contain drivers which are used to drive stepper motors, a power source, circuit built for protection of the controller, interfaces for switch, etc. Grbl shown in figure 2 is a high performance, low cost, open source hardware accompanied with 4 drivers used to drive stepper motors.

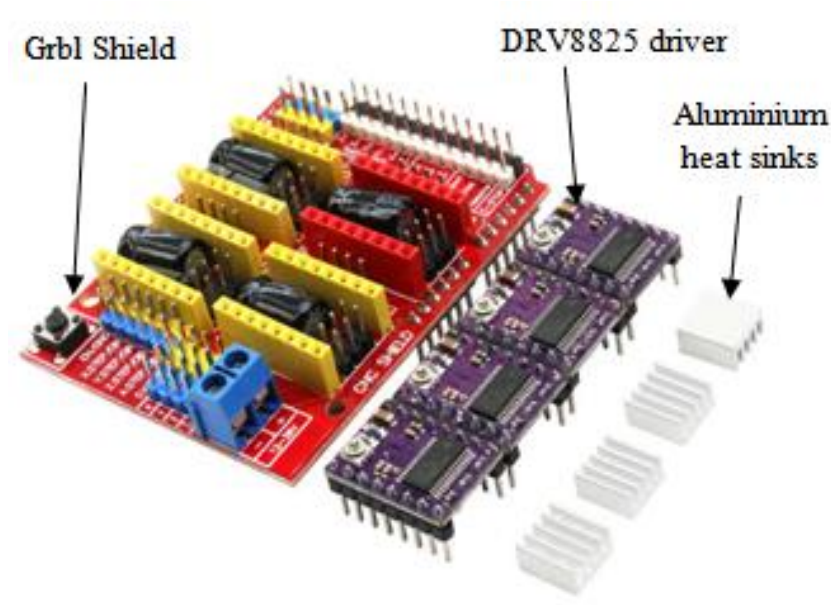

Fig -2: Grbl v0.9 + 4x DRV8825 driver

Arduino Uno shown in figure 3 was the first in the series of Arduino boards (Banzi's et al. 2016) [14]. At the heart of the Arduino is microcontroller chip which can be programmed to do various operations. It also has timing crystal, power regulator, power jack and USB interface.

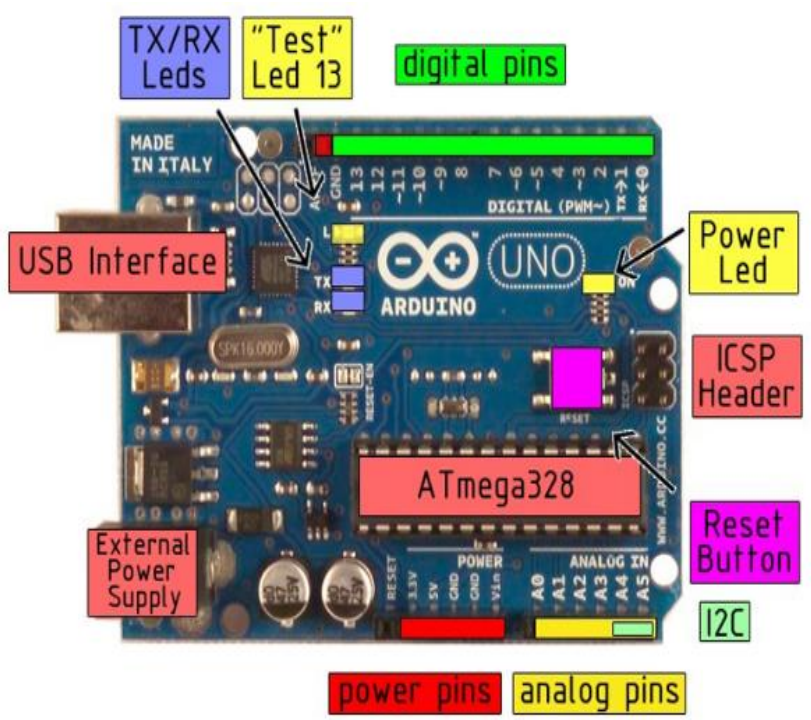

Fig -3: Arduino Uno

Geometry of the profile is extracted from the vectors of the imported .png file as shown in figure 4 and modelling is demonstrated in figure 5.

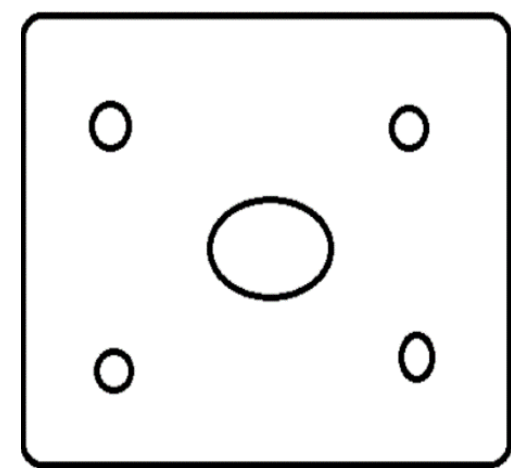

Fig -4:.png file 


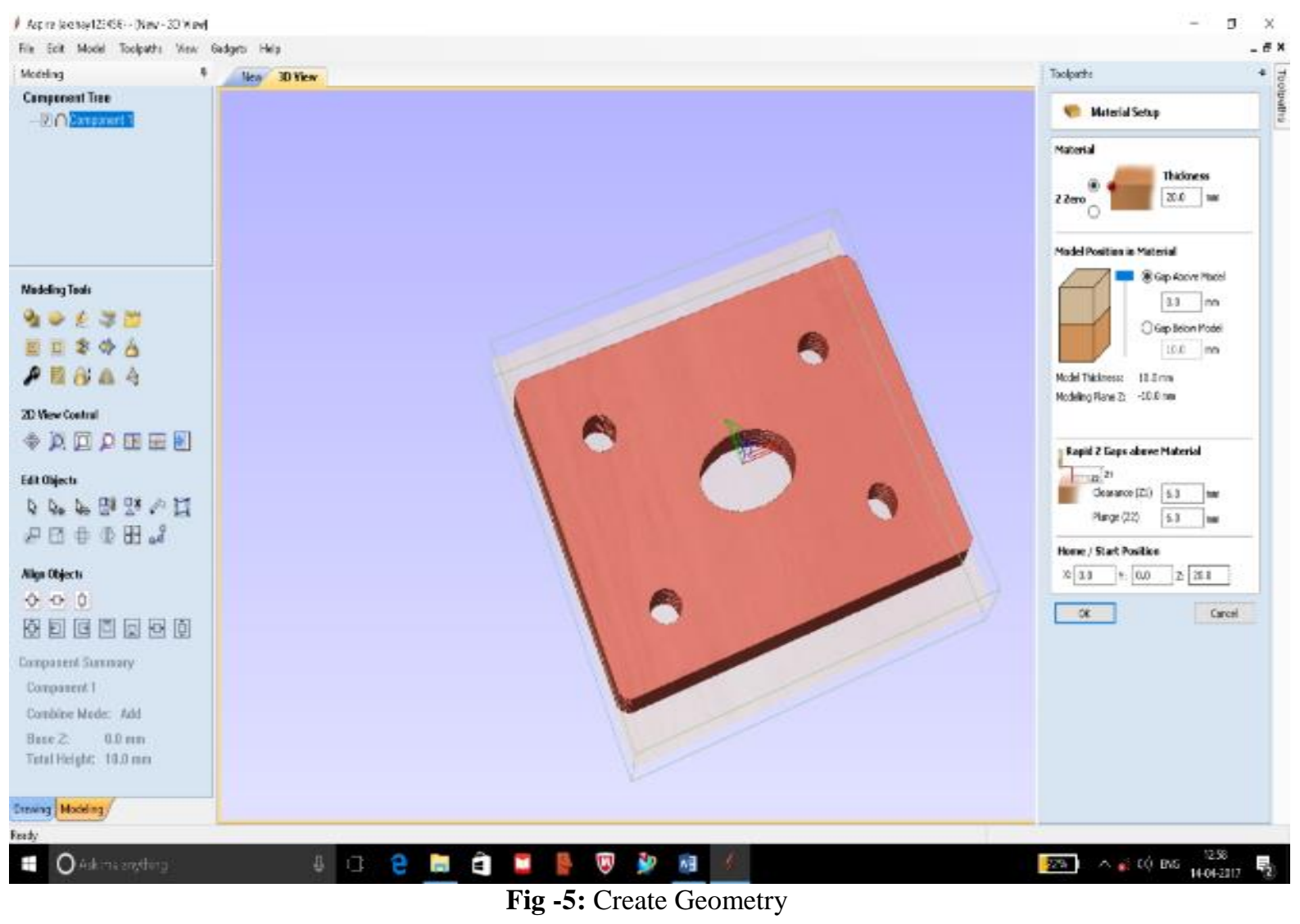

After following modelling procedure and visualizing toolpath as shown in figure 6, the G-code file is generated as shown in figure 7.

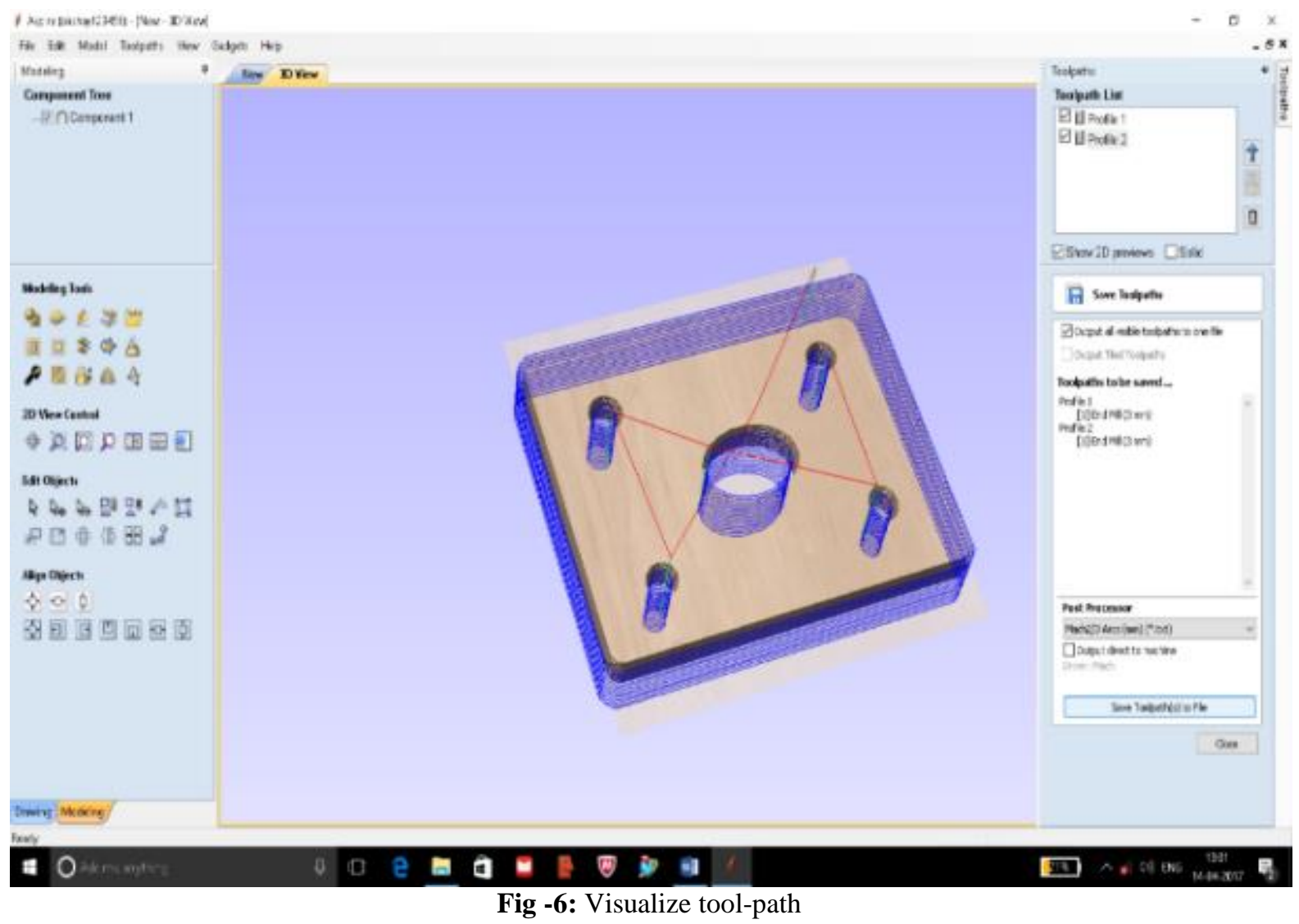




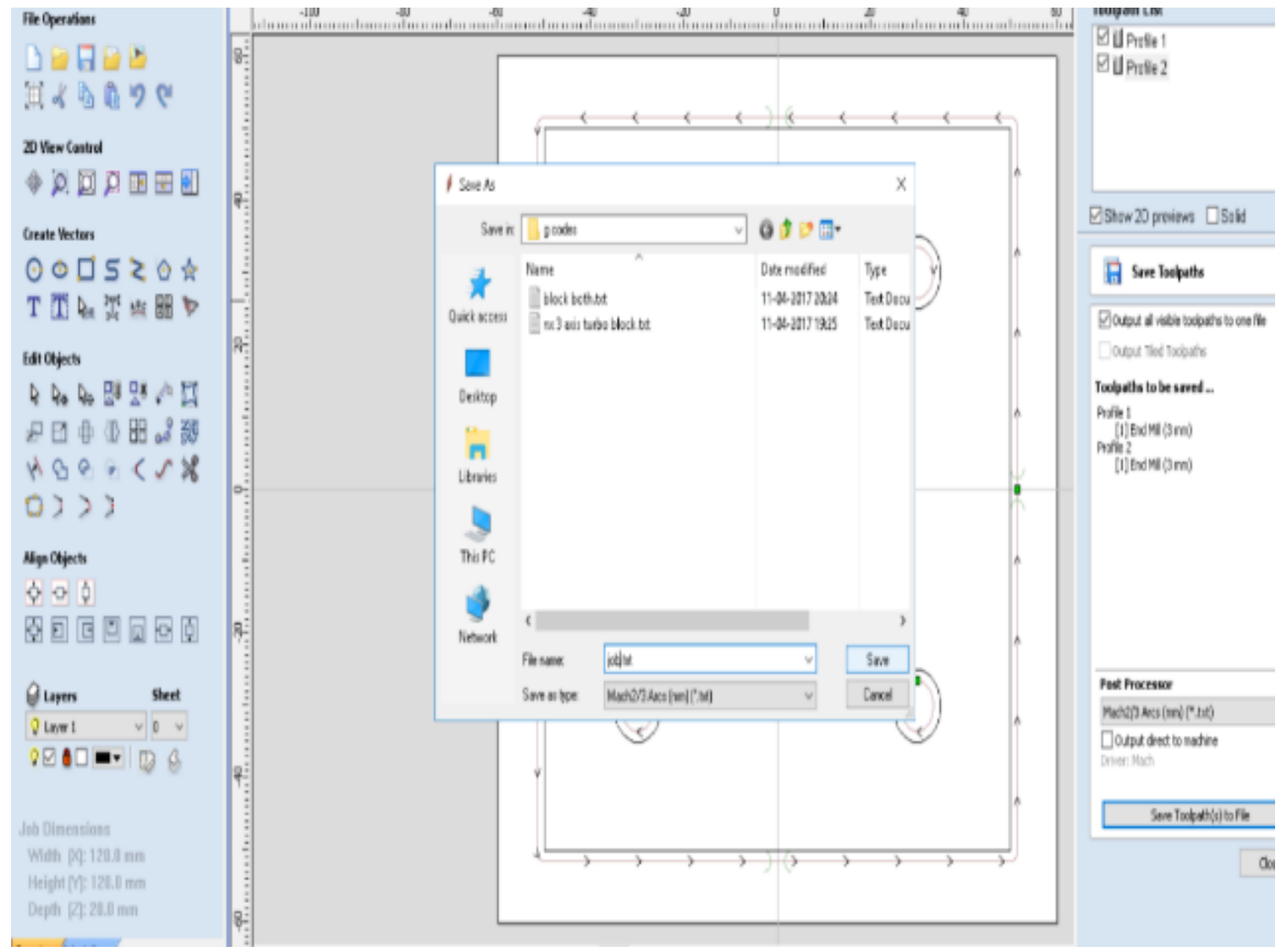

Fig -7: Generation of G-code and M-code file.

Universal G-code sender software takes this file as input to run the steppers motors incorporated to a mechanical system and draw the desired drawing of the featured block. Similar G-code generation process is carried out for other features also.

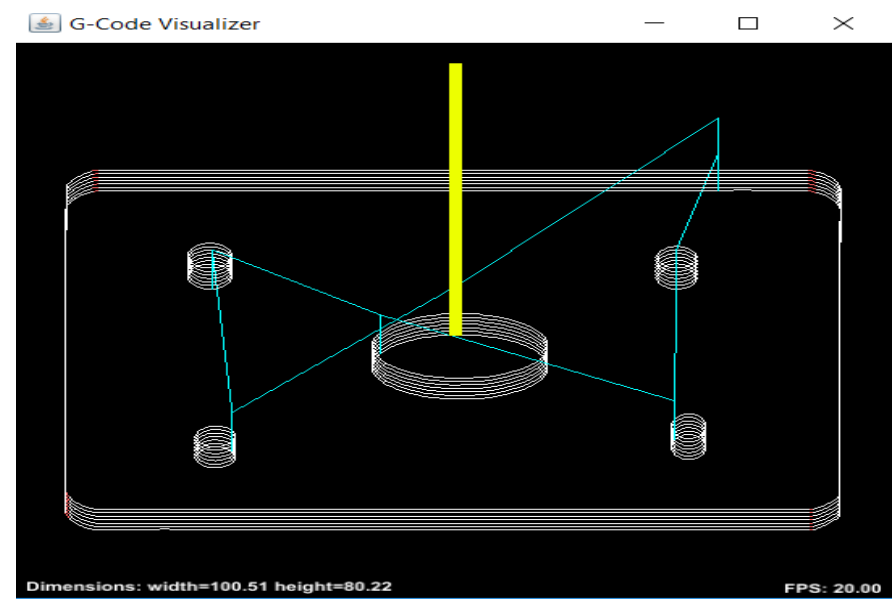

Fig -8: Universal G-code Sender

The tool-path so generated is visualized in universal G-code sender software as shown in figure 8 . The mechanical system assembly on which the generated tool-path is incorporated for machining is shown in figure 9.

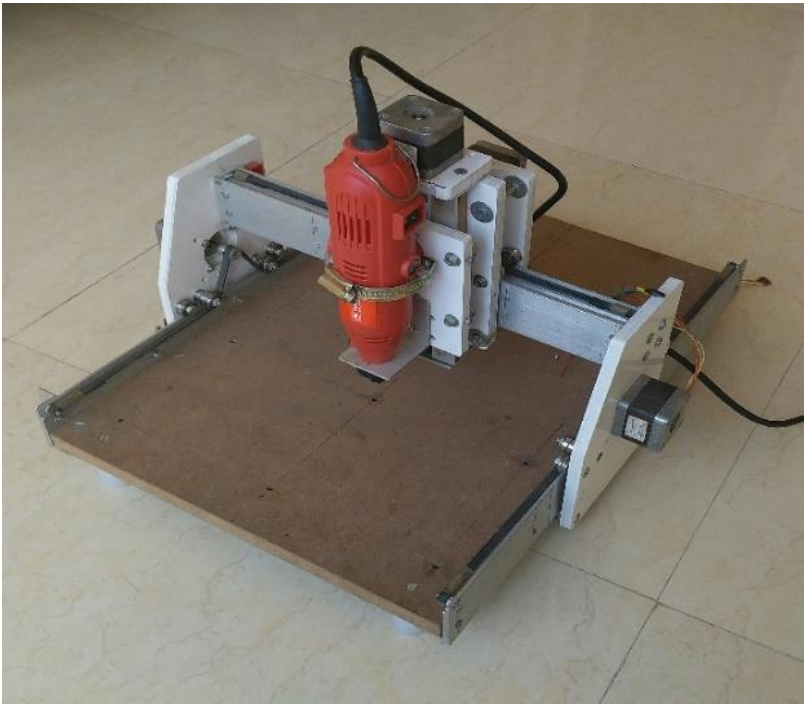

Fig -9: Assembly

\section{CONCLUSION}

An open source universal controller, that can takepreparatory codes (G-code) and miscellaneous codes (M-code) generated by any CAD/CAM softwareis identified. Jpeg or png image of a featured profile is successfully converted into drawing file (.dxf or .prt) and Gcode file is generated for the same after importing it in open source modelling software Aspire. Machining of the above featured profile is shown in figure 10: 


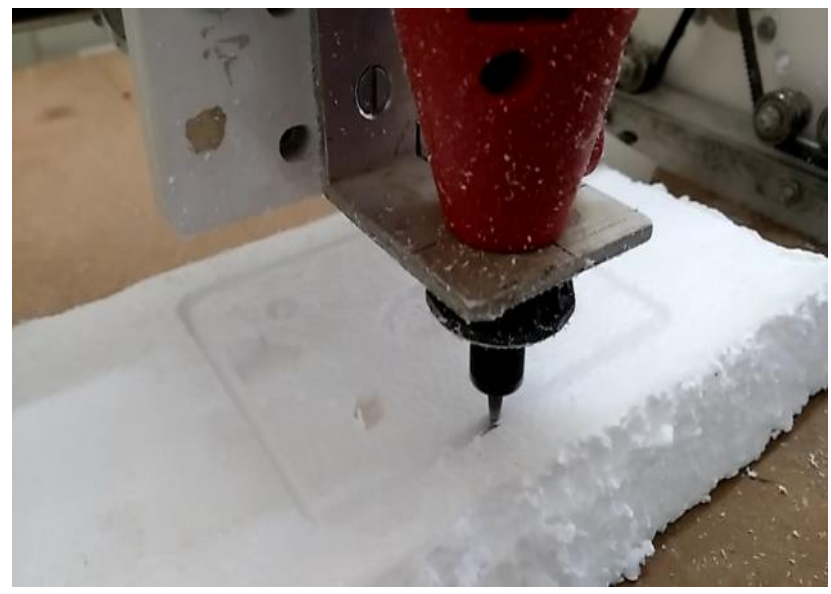

Fig -10: Featured Profile Machining

A simple three axis CNC machine which incorporates four $2.6 \mathrm{~kg} / \mathrm{cm}$ stepper motors, Arduino Uno and GRBL v0.9j + 4x DRV8825 driver with 4 aluminium heat sinks hardware, universal G-code sender software is fabricated. This machine also minimizes the belt error identified in research gap.

This mini 3 axis mill machine prototype acts as an open source CNC machine with open source controller used to machine the profiles. Accuracy and precision is maintained and machine can do various operations like milling, facing, drilling, boring, etc. In this report a simple profile is machined containing four $5 \mathrm{~mm}$ drill, central $30 \mathrm{~mm}$ bore and outer wall facing upto a depth of $5 \mathrm{~mm}$ on soft material viz medium density fiberboard. Due to proper alignment of the belt and the adjustment of the tension in the belt the accuracy is maintained effectively. The profile as modelled above is successfully manufactured with precise accuracy.

\section{REFERENCES}

[1]. Sundar Pandian and S. Raj Pandian, "A low cost build your own 3 axis CNC mill prototype, International journal on mechanical engineer and robotics- ISSN (Print): 23215747, Volume-2, Issue-1, 2014.

[2]. Rajendra Rajput-PG Scholar and Dr. Ajay kumar Sarathe -Assosiate Professor, NITTTR Bhopal "Comparative study of $\mathrm{CNC}$ controllers used in $\mathrm{CNC}$ milling machine, American Journal of Engineering Research- e-ISSN: 2320-0847 p-ISSN : 2320-0936 Volume-5, Issue-4, pp-54-62, 2016.

[3]. Dhaval B Patel- Assistant Professor, Gandhinagar Institute of Technology, Gandhinagar - 382721, and Aniruddh R Kyada- Assistant Professor, Silver Oak College of Engineering \& Technology, "DIY CNC: A REVIEW, 5th International \& 26th All India Manufacturing Technology, Design and Research Conference (AIMTDR 2014) December 12th-14th, 2014, IIT Guwahati, Assam, India $587-1$

[4]. Dipayan Dey, Souvik Mondal and Arijit Kumar Barik, "3 axis CNC router modifiable to $3 \mathrm{D}$ printer, International Journal of Innovative Research in Science, Engineering and Technology, ISSN (online): 2319-8753, ISSN (print): 23476710, Vol. 5, Issue 9, 2016.
[5]. Dr.B.Jayachandraiah- Prof of ME and vice Principal, O.Vamsi Krishna, P.Abdullah Khan, R.Ananda Reddy, Department of Mechanical Engineering Sri Kalahateeswara Institute of Technology, Srikalahasti, A.P, India, "Fabrication of Low Cost 3-Axis CNC Router, International Journal of Engineering Science Invention, ISSN (Online): 2319 - 6734, ISSN (Print): 2319 - 6726 Volume 3 Issue 6\| June $2014 \|$ pp.01-10

[6]. Sakib Shaukat Sarguroh, Arun Bhiva Rane, Saurabh A. Korgaonkar, D. S. S. Sudhakar, 2016, "Elimination of Proprietary Control for Computerized Numerical Control (CNC) Machine," Journal of Basic and Applied Research International, Volume 17, Issue 3, pp. 211-217.

[7]. R.Sundaramoorthy, R Ravindran Assistant Professor, Hindusthan Institute of Technology, Coimbatore, India. Associate Professor, Dr.Mahalingam College of Engineering \&Technology, Pollachi, India "A Literature Survey on machining with different types of materials by CNC milling machine, International Journal of Engineering Sciences \& Research Technology, ISSN: 2277-9655, Feb 2016.

[8]. Kajal Madekar, Kranti R Naraware, Pooja Phadtare and Vikas Mane "Automatic mini CNC machine for PCB drawing and drilling, International research journal of engineering and tech (IRJET), Vol:03, ISSUE:02, Feb 2016 [9]. Alian Albert, FP Innovations Fornitek, "Understanding CNC Routers", 2011.

[10]. Martin Kennedy, January 9, 2016, "Build Your Own CNC Lathe, Mill or Router".

[11]. Patrick Hood-Daniel James Floyd Kelly, 2009, "Build Your Own CNC Machine," ISBN-13 (pbk): 978-1-43022489-1 ISBN-13 (electronic): 978-1-4302-2490-7.

[12]. My Do It Yourself CNC, 2011, version 1.4, "Builder's Comprehensive Plans and Construction Manual".

[13]. Torjus Spilling, 2014 "Self-Improving CNC Milling Machine, Master's Thesis," University of Oslo.

[14]. Banzi Massimo, Cuartielles David, Mellis David, Igoe Tom, Martino Gianluca, Arduino Uno Hardware, Retrieved from https://www.arduino.cc/en/Main/ArduinoBoardUno , on 2016.

[15]. A.B.Rane, S.B.R, and V.K.Sunnapwar, "Strategies to overcome the HR barriers in successful lean implementation" Int. J. of Procurement Management, Vol.9, Issue 2, 2016, pp. 223-247.

[16]. A.B.Rane, V.K.Sunnapwar, and S.M.Khot, "Value Stream Mapping in Lean Manufacturing: A Case Study", $57^{\text {th }}$ National Convention of Indian Institution of Industrial Engineering and $3^{\text {rd }}$ Int. Conference on Industrial Engineering ICIE 2015 at SVNIT, Surat, November 26 - 28, 2015 , Vol.1, pp. 736-741.

[17]. A.B.Rane, D.S.S.Sudhakar, V.M.Mohandas, "Interfacing $\mathrm{CAD} / \mathrm{CAM}$ software to control $\mathrm{CNC}$ machines by eliminating NC codes" at National conference on Signal Processing, Communication and Control (SPCCN01-2005), page no. 309-313, July 2-3, 2005.

[18]. A.B.Rane, S.M.Khot, Sunnapwar and Ramesh V, "Mathematical modelling of Vehicle assembly line for throughput enhancement" Int. J. of Simulation and Process modelling, Vol: 11, Nos. 3/4, pp. 305-325, 2016. 
[19]. A.B.Rane, S.M.Khot and V.K.Sunnapwar, "Assembly line performance and modelling", Journal of Industrial Engineering International, Springer, 2017.

[20]. Router Source, Open vs. closed loop system http://www.cncroutersource.com, 2011.

[21]. A.B.Rane, S.M.Khot, and V.K.Sunnapwar, "Cost models for improved vehicle assembly line performance" Int. J. of Simulation and Process modelling, Vol. 12, Issue no. 2, 2017, pp. 111-123.

[22]. A.B.Rane, V.K.Sunnapwar, and DSSS, "Simulation based case study to improve the Performance of an Assembly Line" at $8^{\text {th }}$ ISDSI International Conference, Pune, India. January 2-4, 2015, published in Trends in Operations Management Perspectives and Challenges, 2016, pp. 91-103.

[23]. A.B.Rane, Chari,V.K.Sunnapwar, M.Sharma, and V.Jorapur, "Improving performance of Lock assembly line using lean and simulation approach" International Journal of Business Performance Management (IJBPM). Vol. 18, Issue no. 1, 2017, pp. 101-124.

[24]. Akshay Sarda, Arun.B.Rane, A.Digalwar, and V.K.S, "Simulation of a Vehicle Assembly Line using ARENA", 57th National Convention of Indian Institution of Industrial Engineering and 3rd Int. Conference on Industrial Engineering ICIE 2015 at SVNIT, Surat, November 26 - 28, 2015,Vol. 2, pp. 857-861.

[25]. A.B.Rane, and V.K.Sunnapwar, "Simulation of Manufacturing system" at International conference on Ecofriendly Technology for Sustainable growth ICEFT-2014, page no. 41-46, March 27-28, 2014.

\section{BIOGRAPHIES}

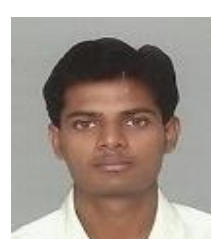

Akshay R Sonawane student of Master's of Engineering has 2 years of Industrial experience and 1 year of teaching experience in one of the degree college of Engineering in University of Mumbai.

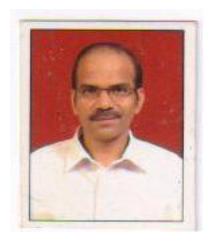

Arun Bhiva Rane obtained his Master's in Production Engineering with distinction from Mumbai University, India. $\mathrm{He}$ is currently pursuing his $\mathrm{PhD}$ in Mechanical Engineering. He has vast industrial experience in the areas of assembly line of moulding machines, vehicle assembly line, CNC machining, tool making and world class manufacturing. Currently, he isworking as an Assistant Professor in Production Engineering. He is teaching forUG and PG students at Fr. Conceicao Rodrigues College of Engineering, Bandra, Mumbai for last ten years.

D.S.S.Sudhakar, Associate Professor and working as a HOD- Production Engineering department in Fr. Conceicao Rodrigues College of Engineering, Bandra, Mumbai. 